\title{
DINÁMICAS SOCIALES, VÍNCULOS Y CONFIANZA EN EL SEGMENTO MEDIO DE LA SOCIEDAD CORDOBESA DEL SIGLO XVII
}

\author{
Social dynamics, links and confidence in the middle segment of Cordoba \\ society of the seventeenth century
}

Constanza María González Navarro*
https://orcid.org/0000-0002-3309-271X

Beatriz Bixio**

http://orcid.org/0000-0002-7433-7744

\section{Resumen}

Las dinámicas sociales de las que hablaremos se localizan en la ciudad de Córdoba (al sur del Virreinato del Perú) y se datan en los primeros ochenta años posteriores a su fundación. Con miras a establecer los mecanismos que motivaron la integración de los miembros de los segmentos medios a la vida activa de la ciudad, que promovieron, a su vez, un cierto reconocimiento y reputación social, nos concentramos en el análisis de un conjunto de sujetos a fin de reconocer sus trayectorias de vida, los vínculos horizontales y verticales que fueron capaces de establecer y sostener y los efectos que produjeron estos vínculos sobre la vida de los sujetos analizados. En este trabajo estudiaremos un tipo específico de vínculos, aquellos que involucran la confianza entre los actores sociales, que se perciben básicamente en relaciones de amor, de amistad, de comercio y de trabajo.

$$
<\text { Sociedad colonial }><\text { Integración social }><\text { Vínculos sociales }>
$$

\begin{abstract}
The social dynamics of which we will speak are located in the city of Córdoba (south of the Viceroyalty of Peru) and are dated in the first eighty years after its founding. With a view to establishing the mechanisms that motivated the integration of the members of the middle sectors to the active life of the city, which promoted, in turn, a certain recognition and social reputation, we concentrated on the analysis of a set of subjects in order to recognize their life trajectories, the horizontal and vertical links they were able to establish and sustain and the effects that these links produced on the lives of the subjects analyzed. In this paper we will study a specific type of links, those that involve trust between social actors, which are perceived basically in relationships of love, friendship, trade and work.
\end{abstract}

$<$ Colonial society $><$ Social integration $><$ Social ties $>$

Recibido: 04/01/2019

Aceptado: 06/05/2019

* Doctora en Historia por la Universidad Nacional de Córdoba. Investigadora adjunta del CONICET (Instituto de Estudios Históricos). Profesora Asistente Instituciones Hispanoamericanas de la Universidad Nacional de Córdoba, Argentina, constanzagn70@yahoo.com.ar

** Doctora en Letras Modernas por la Universidad Nacional de Córdoba. Investigadora Independiente del CONICET (Instituto de Humanidades). Profesora Titular Lingüística I de la Universidad Nacional de Córdoba, Argentina, beatrizb.bixio@gmail.com 
González Navarro y Bixio. Dinámicas sociales, vínculos y confianza en el segmento medio de la sociedad cordobesa...

\section{La sociedad colonial y los segmentos medios}

Desde la fundación de la ciudad de Córdoba (1573) hasta fines del siglo XVII el dominio colonial de la monarquía hispánica en la región fue consolidándose merced al proceso de configuración de la sociedad colonial. Siguiendo a Elias hablamos de "proceso" y de "configuración" porque, en términos generales, un orden social nunca se manifiesta como un producto acabado -sistema social- sino que se entiende como la definición paulatina de límites y particiones; se trata de un proceso de discriminación social creciente que es paralelo a un proceso de individuación y a una cada vez mayor intervención estatal que actúa mediante coerciones y controles de las prácticas, emociones, deseos y subjetividades. Aceptamos con Elias (2009 [1977]) que la investigación más que develar una "estructura social" -equilibrada e inmutable-, asignará una forma a la "composición" social, como un entramado de interdependencias constituido por individuos.

La configuración de la sociedad colonial cordobesa fue posibilitada por la existencia de una población indígena autóctona sometida al dominio colonial hispánico desde la segunda mitad del siglo XVI y por el continuo aumento poblacional resultante de la migración de origen peninsular o de otros territorios coloniales de la Monarquía hispánica, de regiones europeas, de los traslados de población africana esclava y de las migraciones de indígenas desnaturalizados del Chaco y de los Valles Calchaquíes. El proceso de mestizaje biológico también fue un aspecto clave. El lugar social pasible de ser ocupado por cada uno dependió de factores que muchas veces trascendían la variable étnica, tales como las redes sociales construidas, la lengua, la configuración cultural, el vestido, la inserción en el mercado de trabajo y de bienes, etc.

Desde hace unos años estamos interesados en el estudio de aquellos sujetos, que sin constituir un grupo en el sentido sociológico del término, se ubican en el "entre" de los grupos legal y fiscalmente estatuidos (república de españoles / república de indios), o de los extremos socialmente constituidos -indios encomendados, esclavos/ miembros de la elite. Los integrantes de este segmento social no formaron parte de los sectores de poder económico y político de la región (como los encomenderos, grandes comerciantes o tratantes, estancieros, obispos), ni tampoco de los subalternos propiamente dichos (esclavos e indios de encomienda). En efecto, la élite local estaba representada por el grupo de vecinos beneméritos o sus descendientes que habían pasado a constituir el grupo con acceso a la tierra y al trabajo indígena a través de la concesión de títulos de merced y encomienda. Este segmento tenía el control político del cabildo y se encontraba vinculado al comercio interregional. Junto a ellos, los grandes comerciantes -algunos de los cuales también eran tratantes de esclavos- representaban el sector más poderoso económicamente y que tuvo la capacidad de acomodarse a los avatares de los polos de desarrollo mineros y la caída demográfica de la población indígena, para reorientar sus actividades económicas en otras direcciones -como es el caso de la producción y engorde de mulas- (Assadourian, 1982). En el otro extremo de la escala social se situaron los indígenas incorporados al sistema de encomiendas que sufrieron un descenso poblacional en términos de catástrofe durante los primeros 30 años de 
asentamiento hispánico y los esclavos de origen africano, que ingresaron a Córdoba pero que fueron derivados a otras regiones, en particular, Potosí, y recién a partir de 1620-30 empezaron a ser absorbidos por las unidades de producción rural de la región -estancias mixtas-(González Navarro, 2005).

Por su parte, los segmentos medios, constituidos principalmente por población de origen peninsular (españoles y portugueses), pero también españoles nacidos en América y mestizos, conformaron una amplia franja de población que garantizó el afianzamiento de una joven ciudad como Córdoba, a través del trabajo artesanal, los servicios profesionales y el comercio a pequeña escala. En general este sector ha recibido poca atención de los historiadores colonialistas tanto en ésta como en otras latitudes ${ }^{1}$.

Si bien, para el hombre de la colonia hay un orden en el cual cada uno tiene su lugar según el origen familiar, el color de la piel, la vestimenta, el vocabulario, la lengua que se habla u otros símbolos visibles o diacríticos (Muchembled, 1998, pp. 168; Presta, 2000; Saldanha Alvarez, 2007), en este segmento encontramos un abanico étnico variado, heterogéneo y de cambiante constitución en el tiempo, cuyo rasgo específico no radica en un origen biológico o étnico común, sino que se relaciona con una acentuada movilidad espacial y, en la mayoría de los casos, ocupacional; una destacable adaptabilidad, un nutrido capital experiencial, búsqueda de reconocimiento social, carencia de una prosapia o linaje de sangre, alta vulnerabilidad y ambigüedad y otro conjunto de rasgos que se relacionan con el tipo de vínculos interpersonales que establecen, las emociones, creencias y sensibilidades que sostienen.

Nuestro trabajo parte, en primer lugar, de ciertos avances previos del equipo de investigación, realizados respecto del proceso de configuración de la sociedad colonial cordobesa (González Navarro, 2009; Rubiolo Galíndez, 2013; González Navarro, 2013; Tapia, 2016; Bixio, 2013). En esta oportunidad, proponemos adentrarnos en esta franja social a partir de los vínculos que sus miembros fueron capaces de construir -y sus efectos-, partiendo de una muestra de un conjunto de 140 casos de sujetos individualizados en variados tipos de fuentes -ubicadas cronológicamente entre 1573 y 1620-, seleccionados no por su origen étnico sino porque: 1) detentaban un savoir faire específico que les proporcionó un medio de vida u oficio lucrativo, una actividad comercial o tipo de servicio en la ciudad de Córdoba, 2) no se encontraban en filiación directa con las familias de vecinos beneméritos, no detentaban cargos en el cabildo ni funciones públicas, 3) no estaban sujetos a vínculos de dependencia a perpetuidad (como la encomienda o la esclavitud).

La tarea heurística implicó el relevamiento de los 35 primeros tomos de registros de protocolos de escribanos del Archivo Histórico de la Provincia de Córdoba (Registro $1)^{2}$ donde se identificaron: contratos de trabajo de artesanos y aprendices, formación de compañías, cartas de obligación, cartas de fianza para apertura de pulperías, todos

Una síntesis de estos abordajes puede verse en: Bixio y González Navarro, 2019.

Se ubican cronológicamente entre 1573 y 1620 . Se continúa con la tarea de relevar este registro para los años posteriores. 
González Navarro y Bixio. Dinámicas sociales, vínculos y confianza en el segmento medio de la sociedad cordobesa...

documentos que dan cuenta de que los sujetos identificados vivieron y tuvieron asiento en la ciudad - y no sólo transitaron- en un momento de sus vidas.

Complementariamente, se ha utilizado, además, la información proveniente de una selección de expedientes sucesorios y pleitos que involucran a miembros del segmento medio, ya sea como actores de la causa o testigos (ver apéndice final) ${ }^{3}$. El fondo de justicia, permite, en efecto, reconocer el accionar y los conflictos derivados de la interacción de los sujetos analizados. En este mismo fondo, los testamentos e inventarios de bienes contenidos en los juicios sucesorios son útiles para analizar las trayectorias de vida, los lazos sociales, las acreencias y las deudas. Finalmente, se ha trabajado con el $100 \%$ de las actas capitulares conservadas correspondientes a este período, aunque se han identificado algunos faltantes de días o unos pocos meses de actas de sesiones de cabildo.

\section{Problema e hipótesis}

Las dinámicas sociales de las que hablaremos se localizan en Córdoba (extremo sur de la colonización americana del lado Este de la cordillera) y se datan en los primeros ochenta años posteriores a su fundación, período inicial de configuración de un orden social inestable, con muy pocos habitantes, que respondió, como en otros establecimientos coloniales iniciales, a criterios bastante sui generis de organización social, en los que los vínculos y las ubicaciones de los sujetos en cuadros clasificatorios aparece desdibujada, con imperfecciones y ambigüedades. Estimativamente para 1606 el gobernador del Tucumán, Alonso de Rivera, informaba al rey que Córdoba contaba con 60 vecinos y 6.113 indios reducidos (Segreti, 1999, p. 39). Para 1647, las actas capitulares de la ciudad registraban un listado de contribuyentes del impuesto unión de armas con 138 vecinos hombres y 19 mujeres viudas ${ }^{4}$. Estos datos demográficos son apenas indicativos y nos permiten tener una idea del volumen de la población avecindada y propietaria de la ciudad. Nada nos dicen acerca de los segmentos medios propiamente dichos, muchos de los cuales no alcanzaban nunca a ser vecinos.

Con miras a establecer los mecanismos que motivaron la integración de los miembros de los segmentos medios a la vida activa de la ciudad, que promovieron, a su vez, un cierto reconocimiento y reputación social, nos concentramos en el análisis de un conjunto de sujetos a fin de reconocer sus trayectorias de vida, los vínculos horizontales y verticales que fueron capaces de establecer y sostener y los efectos que produjeron estos vínculos sobre la vida de los sujetos analizados.

El modelo propuesto por Elias ha resultado especialmente apropiado para el estudio de la integración social y los vínculos que la habilitaron pues, para este autor, la composición social es, justamente, este entramado de seres humanos que establecen

\footnotetext{
3 Una fuente muy valiosa que se ha consultado dentro de este fondo son los expedientes de tutoría de menores, donde los tutores presentan recibos de pago por los gastos y allí se detectan numerosos registros de servicios o bienes adquiridos a manos de miembros de los segmentos medios. V.gr. Tutoría de Alonso y Ana de Salvatierra. Esc. 1, Leg. 17, Exp. 12. Año 1605.

4 Actas Capitulares. 4-I-1647. En: Luque Colombres, 1952, p. 396.
} 
vínculos de interdependencia unos con otros, lazos que se desarrollan a través del tiempo, que supera la perspectiva del "homo clausus" y de la sociedad como una entidad independiente que se impone a los individuos (Elias, 2009, p. 58; 2000, p. 161). La perspectiva de Elias en su vertiente de una sociología de los vínculos, resultó apropiada para nuestro trabajo en el que buscamos conocer cómo se enlazan las posiciones de los sujetos en redes de relaciones de interdependencia con un fuerte componente emotivo. Si bien no conocemos otras investigaciones que hayan usado este modelo con los objetivos que aquí nos proponemos, cabe advertir que las categorías sociológicas e históricas de Elias han resultado especialmente fructíferas para la investigación sociológica, de historia social, historia política, historia de la cultura y de los símbolos culturales, del funcionamiento de las cortes virreinales americanas, disciplinamiento social, entre otros (Vgr.: Breton y García, 2003; Araya Espinoza 2006; Bridikhina, 2007; Mantecón Movellán, 2010; Undurraga y Schüler, 2010; Ansaldi y Giordano, 2012, por citar sólo algunos estudios del período colonial americano).

Los fragmentos de historias de vida que hemos alcanzado a reconstruir de personas pertenecientes a estos segmentos intermedios habilitan la hipótesis de que tanto los trabajos (o estrategias) para la construcción de vínculos, como sus reglas, modalidades y efectos fueron diferentes de los que caracterizaron a la elite. El ascenso de estrato de sus miembros estuvo, en términos generales, bloqueada por una serie de circunstancias que sólo parcialmente pudieron escamotearse mediante la construcción de vínculos. Sin embargo, es dable también reconocer que, en no pocos casos, estos mismos vínculos funcionaron como condiciones de posibilidad de la mejora en las condiciones de vida en tanto permitieron afrontar adversidades de todo tipo, tal como puede reconocerse como característica más notoria de la elite. Es más, cuando estos vínculos faltaban, el sujeto podía fracasar estrepitosamente a mitad de un proceso de ascenso. En este sentido, cobra relevancia la afirmación de Ponce Leiva según la cual estas relaciones verticales constituyen una arena que habilita la comprensión del cambio social:

"El estudio de las redes sociales, en general, y de las relaciones verticales, en particular, interesa también por la posibilidad que ofrece de estudiar dinámicas sociales, de "cambios", de "continuidades" y de "heterodoxias", pero siempre entendidas como respuestas de los individuos ante las cambiantes situaciones que se les presentan" (Ponce Leiva, 2007).

Este reconocimiento amerita una observación relativa al hacer referencia a "cambio social". Este concepto ha variado su acepción desde que se lo considerara como cambio en la estructura u orden social o en los modos de producción que supone cierta finalidad social. Hoy se emplea mejor la noción de "dinámica social", en oposición a inmovilismo social, que da cuenta de los procesos a partir de los cuales las relaciones entre los elementos pueden sufrir variaciones dando lugar a una ordenación diferente que implica una superación de las oposiciones particulares (de sexo, edad, estatus, rol, etnia, etc.). Ese cambio, siempre involucra nuevas relaciones sociales pero también redefiniciones a nivel de las sensibilidades y las identidades de las personas. 
González Navarro y Bixio. Dinámicas sociales, vínculos y confianza en el segmento medio de la sociedad cordobesa...

Lo interesante es que, esta nueva relación entre los elementos puede realizarse sobre viejas categorías mentales que deben, sin embargo, sufrir algún desplazamiento. Así, tanto la legislación como la moral o la religión pueden legitimar ciertos vínculos que los sujetos aceptan como legítimos, pero que sin embargo no son capaces de respetar (distribución más o menos homogénea de la creencia en la forma legítima del orden social y heterogénea distribución en relación a las prácticas). Estas representaciones mentales sobre las cualidades que debe tener el orden social se pueden reconocer tanto en expresiones explícitas, como en prácticas o discursos, en especial, cuando se relacionan con las identidades asumidas, simuladas o asignadas.

Intentamos establecer una relación entre "integración social" y vínculos tanto previstos como no previstos, esto es, considerados al margen de la doxa. Si estas relaciones heterodoxásticas fueron posibles entre los sectores medios y no marginaron a los sujetos -o sea, no obturaron su integración social- es porque, de alguna manera, los criterios de legitimación del orden social las habilitaron. Es esta tensión entre las creencias compartidas y las prácticas disidentes lo que establece una distinción de estos segmentos intermedios, según hipotetizamos.

La integración puede ser reconocida a partir de un conjunto variado de indicadores, entre los cuales destacamos la acumulación de diversos tipos de capital, categoría de residencia (vecino, residente, morador, estante), calidad de propietario de un inmueble, matrimonio con personas de la ciudad, lugar de residencia (en la traza de la ciudad y en relación a la oposición ciudad-campo), actividades realizadas, entre otros, pero fundamentalmente, vínculos que puedan haberse establecido. Cabe advertir que cuando hablamos de vínculos o relaciones establecemos metodológicamente que el "ego" de estas relaciones es un individuo perteneciente a los segmentos medios.

En esta oportunidad estudiaremos un tipo específico de vínculos, aquellos que involucran la confianza entre los actores sociales, que se perciben básicamente en relaciones de amor, de amistad, de comercio y de trabajo. La confianza es una de las fuerzas más poderosas entre los seres humanos que estimulan los vínculos y activan lazos sociales, así como posibilitan la vida en sociedad. A la vez, la confianza es la llave de la integración social. Podríamos haber incluido otros vínculos asentados en la confianza como la tutoría, el albaceazgo, la testificación, el compadrazgo, etc. Algunos de éstos son diádicos y simétricos, de modo que suponen que ambas partes participan de manera igualitaria en ella (la confianza es mutua en una sociedad comercial, por ejemplo o en la consignación o el préstamo), mientras que otros son asimétricos y unidireccionales, en tanto suponen que una de las partes del vínculo confía en la otra sin que la relación sea necesariamente reversible (tutoría, albaceazgo); otros son más difíciles de identificar (como en el caso del amor y el compadrazgo). Nos parece importante esta distinción porque no en todos los casos esta direccionalidad de la confianza está en relación con la verticalidad $\mathrm{u}$ horizontalidad del vínculo.

Analizaremos tres modos de manifestación de la confianza en la antigua Córdoba del Tucumán: el vínculo amoroso (no necesariamente de pareja), el vínculo de amistad y el vínculo comercial y laboral (de intercambio de bienes y conocimientos), 
lo que nos permitirá algunas observaciones sobre la dinámica social que inscriben. Hay que tener en cuenta que tales vínculos son móviles y sufren transformaciones a lo largo de la vida de un sujeto, en otras palabras, los vínculos tienen por cualidad la fragilidad.

\section{El lazo amoroso}

La expresión "vínculo afectivo" da cuenta de la capacidad del amor para establecer relaciones con otros seres humanos; se trata de una noción de Elias que se construye para dar cuenta de las relaciones que se establecen entre las personas en clave emocional (Elias, 1999, p.159). Los amantes, para Simmel, considerados como unidad sociológica, "son una relación" (Simmel, 1986, p. 665), es más, son una relación elemental, tanto en su carácter de eslabones fundantes de la sociedad (Elias, 1999, p.160), como en su carácter de necesidad humana elemental:

"La necesidad de amar y ser amado es, por así decirlo, la concreción más intensa de este requerimiento natural de los seres humanos, que puede también tomar la forma del dar y recibir amistad" (Elias, 2000, p. 231).

El amor, como sucede con todas las pasiones, debe ser historizado en tanto fue construido y vivido de muy diversa manera a lo largo de la historia (Gonzalbo Aispuru, 2013), forjando subjetividades y sociabilidades 5 . No hablamos del amor de amantes -sólo una de las manifestaciones del vínculo amoroso- ni tampoco del amor romántico o moderno, erótico, ni siquiera del amor de pareja. Nos referimos a las relaciones amorosas, de cariño, sea de pareja, sea filiales, sea entre amigos, que significan el reconocimiento del otro, su cuidado, atención, su protección, de manera más o menos gratuita, y lógicamente, la confianza en ese otro. Serge Paugam ha destacado que tanto la protección como el reconocimiento definen propiamente al vínculo social. La primera consiste en "el conjunto de soportes que el individuo puede movilizar ante los avatares de la vida (recursos familiares, comunitarios, profesionales, sociales)" y la segunda "remite a la interacción social, que estimula al individuo a proveerle de la prueba de su existencia y de su valor a través de la mirada del otro o de los otros" (Paugam, 2012, p. 2) ${ }^{6}$. Intentaremos especificar qué tipo de protección y reconocimiento habilita y construye el vínculo amoroso, aunque es claro que lo que varía en estos diferentes planos de manifestación del pronombre "nosotros" es la carga emocional y el grado de compromiso del vínculo amoroso, que se

\footnotetext{
5 En términos de Elias el proceso de individuación que caracteriza al proceso civilizatorio es también un proceso de privatización de estos vínculos y de los espacios en los que ellos se manifiestan. En efecto, el espacio privado de la alcoba o del baño puede interpretarse como resultado de la privatización de ciertas relaciones y modos de la sensibilidad como el pudor o la vergüenza (Elias, 1998, pp. 364-365).

6 "En la mayoría de los actos de la vida cotidiana, el individuo está, por así decirlo, bajo la influencia de la mirada del otro, no ya sólo para obligarle a actuar conforme a las reglas y las normas sociales, sino también y sobre todo para satisfacer su necesidad vital de reconocimiento, fuente de su identidad y de su existencia en tanto que hombre. El individuo busca en cierta medida una aprobación en el vínculo que teje junto a otros" (Paugam, 2012, p. 4).
} 
González Navarro y Bixio. Dinámicas sociales, vínculos y confianza en el segmento medio de la sociedad cordobesa...

pueden reconocer en una línea continua y gradual. Nos referimos, claro está, a los vínculos amorosos con "valencias" abiertas o positivas?.

Hasta donde hemos podido constatar, la posibilidad de que los vínculos redunden en cambios sociales para sujetos individuales de los segmentos medios parece que se aplica, particularmente, para el caso de aquellas relaciones en las que está involucrado el amor y el cariño. Los testamentos de esta región y período permiten observar con claridad con cuánta frecuencia el amor habilita un legado extraordinario que puede mejorar con mucho las condiciones de vida de los beneficiarios, ampliando el campo de efectos económicos de la muerte a sujetos no previstos. En estos casos, se especifica que esta donación -que no responde a obligaciones impuestas por ley-encuentra su justificación en el amor o cariño, generalmente, de naturaleza filial, con la fórmula iterativa "por el mucho amor que le tengo".

Esta expresión de amor se encuentra en testamentos, donaciones y cartas de dote, aunque es más común encontrarla en testamentos, discursos complejos con finalidades múltiples, formularios, que cabalgan entre la ley estatuida sobre la herencia y las mandas forzosas, las acciones estipuladas para alcanzar "el camino de la salvación” y el deseo del testador en cuanto a la disposición de sus bienes. Por ello, se ubica en el entremedio de las modalidades del querer y del deber'.

Esta fórmula no acompaña toda donación, como se ha relevado para otras regiones (García Fernández, 1994, p. 246), sino algunas pocas, de allí su relevancia pues se encuentran frecuentemente en aquellas situaciones anómalas, que ameritan ser justificadas, porque los legados se direccionan hacia miembros fuera de la familia y se relacionan, por ejemplo, con dotes que se asignan a mestizas hijas naturales -propias o de algún amigo-, con la liberación y donación de bienes a esclavos, etc. En general, los datos con los que contamos no innovan respecto de las modalidades estatuidas de transmisión de la herencia pero, como advirtiera Gómez Carrasco (2009), es interesante adentrarse en las desviaciones a la norma en relación a decisiones más amplias que pueden involucrar estrategias de reproducción o redes de parentescos complejos, solidaridades y afectos, reconocimientos de servicios, etc. Esto es, las estrategias hereditarias tienen sentido, en nuestro caso, si se pueden contextualizar en efectos amplios.

\footnotetext{
7 Los seres humanos se enlazan con los otros desde diversas valencias afectivas (Elias, 1999, p. 408).

8 Esta fórmula iterativa, es una demostración más de que hay un cierto vacío en la documentación de las expresiones de afecto y una ausencia de gestos de cariño (Gonzalbo Aizpuru, 2013). Nunca podremos asegurar hasta qué punto estas expresiones de afecto se corresponden con afectos efectivamente vividos y sentidos. Sólo el discurso y las conductas de los sujetos.

9 Es así que la expresión formularia "por el mucho amor que le tengo" no puede confundirse con la expresión "para descargo de mi consciencia", que puede aparecer en las mismas conlocaciones que la anterior en el sentido que ambas, en un testamento, justifican donaciones o legados extraordinarios, pero que nos posicionan frente a dos tipos de vínculos diferentes: el amor y por ello, el deseo de mejorar a alguien con parte de la herencia; el temor y por ello, el deseo de equilibrar los daños ocasionados a alguien durante la vida, saldar las deudas con los sobrevivientes, como vía también para saldarlas con dios y así garantizar el acceso al cielo. Ambas fórmulas actualizan diferentes modalidades de la enunciación.
} 
El amor entre iguales es común y aparece profusamente en la documentación, la mayoría de las veces de manera implícita, y se relaciona básicamente con las relaciones familiares o de amistad: el amor a un vecino a quien se ama y por ello se lo ayuda o se le ofrece un pequeño legado por vía testamentaria; o como amistad entre sujetos que se salvan mutuamente de deudas; o la mejora por vía testamentaria o por dote a una hija o nieta "por el mucho amor que le tengo"10.

Los miembros de los segmentos medios o subalternos tenían bastante bloqueado el acceso a la elite mediante el casamiento u otro mecanismo, pero sí fue posible que estas relaciones verticales de amor habilitaran cambios relevantes en las condiciones de vida y en las mentalidades de los grupos medios e incluso inferiores. En otras palabras, cuando el sujeto que amaba y cuidaba pertenecía a un estrato superior habilitaba a un inferior a acceder a cierto reconocimiento social, diferente al que tenía antes de tal protección, o a un cambio extraordinario en su posición y pasar desde las escalas más bajas de la sociedad al estamento intermedio por el amor.

Un caso excepcional, pero digno de atención es el de la negra Antonia ${ }^{11}$ que por el amor que le tenía su ama cambió radicalmente su posición (de esclava a libre, casada con portugués, dueña de una pequeña fortuna, con esclavos) y de sus hijos, que también dejaron de ser esclavos (a excepción de uno de ellos). En efecto, la situación de la esclava Antonia, pudo dar un giro hacia su emancipación e integración a los segmentos medios por decisión de su ama, María Cortés quien le otorgó la libertad por testamento antes de morir. Fue el amor de su ama, que la crio desde niña, lo que posibilitó este ascenso. También le legó una esclava, Esperanza, con su cría, cuando contrajo matrimonio y aún era esclava. De modo asistimos a la situación del todo anómala de una negra esclava que, a su vez, tenía esclavos a su servicio.

Al momento de testar, su posición económica era buena y exhibía una fuerte mimetización con los sectores altos y medios: pide que se la entierre con "una misa cantada con su vigilia y acompañe mi cuerpo el cura y sacristan con cruz alta"12; pide veinticuatro misas en razón de ocho reales cada una, ofrece cuatro reales a cada manda forzosa, usa sarcillos y una crucecilla de oro. Incluso, pueden reconocerse, como pocas veces sucede entre los miembros de esta franja intermedia, objetos artísticos o suntuarios como un lienzo de pintura de Nuestra Señora del Rosario con su moldura dorada. Duerme en una cuja con pabellón. Su vestido no la delata en su calidad social: su ama la vistió de modo que no parecía una esclava ("y assi mismo me dio de vestir con decencia como que fuera mujer libre y no su esclava"13).

También se advierten otros lazos de Antonia con lo más encumbrado de la sociedad que, de alguna manera, formaron parte de la herencia de su ama, quien le legó más que una nueva condición jurídica y bienes materiales. Por un lado, Adrián Cornejo,

\footnotetext{
${ }^{10}$ Sebastián Casero, mayordomo del obraje de Soto, deja en el testamento una mejora a su esposa india: "Yten mando se le de de mis bienes el quinto a mi mujer por la obligasion y amor que la he tenido". AHPC. Esc. 1, Leg. 80, Exp. 2. Año 1640.

${ }^{11}$ AHPC. Esc.1, 1655, Leg. 4, Exp. 3. F. 186r-188r.

${ }^{12}$ AHPC. Esc.1, 1655, Leg. 4, Exp. 3. F. 186r.

${ }^{13}$ AHPC. Esc.1, 1655, Leg. 4, Exp. 3. F. 187r.
} 
González Navarro y Bixio. Dinámicas sociales, vínculos y confianza en el segmento medio de la sociedad cordobesa...

sobrino de doña María Cortés, cura y comisario de la Santa Inquisición en la ciudad, quien le había prestado una cuja, era amo de uno de sus hijos, esclavo, en una relación vincular confusa, que nos advierte sobre el carácter aún subordinado y de dependencia de Antonia. Fue nombrado albacea, junto a su propio marido. Antonia mantuvo además, relaciones con dos de sus hermanas a las que expresa su voluntad de dejarles por herencia una pollera y una mantelilla negra, tomados del quinto. También expresaba relaciones con religiosos de la ciudad, como el padre Esteban García. Nombraba por herederos a sus seis hijos, mejorando con el tercio a su hija Juana, "recoxida en el monasterio de sancta Catalina de Sena". No firmó.

Se observa que su mimetización con los sectores medios y altos era significativa. El vínculo con su ama, no sólo había producido un cambio social en la esclava, lo que es más destacable es el cambio cultural y en sus representaciones pues en su testamento se mostraba como una persona que había internalizado en sus detalles la cultura y la mentalidad hispánica colonial.

Antonia contaba con un inmueble ubicado frente a la plaza, donde su marido trabajaba como sastre. No hay datos en los documentos con los que contamos para inferir que sufriera algún tipo de descalificación social por su origen esclavo o por el color de su piel. Esto es, entre los miembros del segmento medio, al que claramente pertenecía ella y su marido, podía moverse con soltura. En este caso, Antonia pudo integrarse como un miembro pleno a la sociedad cordobesa en función de estos vínculos, entre los cuales el casamiento fue tan definitorio como lo fue el amor de su ama. Es esta suerte de familia que logró componer lo que permitió que Antonia pudiera superar tan alevosamente la trayectoria prescripta en función de su origen étnico. Este vínculo, también, habilitó el cambio cultural necesario para tal integración social: era cristiana, pensaba, vivía, vestía y actuaba como una española.

En su testamento Antonia se mencionó por el nombre, sin apellido ni rasgos étnicos. No se autodefinía como "negra" ni como mulata, o algo así, lo que sí solían hacer los indios. Lo que en su autoidentificación resulta relevante es el nombre y el hecho de que fuera "mujer legítima de Pedro López, oficial maestro de sastrería”. Nunca dijo ser negra, se infiere de su calidad de esclava. Su identidad buscó ser construida a partir de un nombre propio y un vínculo marital, pauta de la difusión a todos los estratos de los rasgos de la sociedad dominante. Su marido, indio de Santiago del Estero llamado Pedro López, fue aceptado en la ciudad como maestro sastre, tuvo gran reputación en su oficio, vestía como un español y llevaba, incluso, espada y daga. La estrecha relación que estableció con la ama de su esposa, María Cortés ${ }^{14}$, protectora de su mujer, fueron sin duda, los móviles más relevantes para que este indio actuara en la ciudad con las mismas prerrogativas que un español artesano ${ }^{15}$. En su testamento disponía que todos sus hijos (todos con Antonia, de su primer matrimonio) sirvieran en calidad de criados al doctor Adrián Cornejo, signo también de la internalización de la relación clientelar construida por este sobrino de doña María Cortés.

\footnotetext{
${ }^{14}$ Este caso es mencionado también por Eduardo Gould, 2008.

${ }^{15}$ AHPC, Esc.1, Leg. 104, Exp. 3, Año 1655.
} 
La relación vincular benefició ampliamente a la familia de Antonia y se tradujo en cambios a nivel de su ubicación social y la de su familia. Sin embargo, los vínculos heredados, en especial con el comisario de la Inquisición, que era sobrino de su ex ama extendieron el ejercicio de una autoridad y de una relación de subordinación a los hijos de Antonia, a pesar de que también actuaron como acción solidaria. Y ello es así porque, como advirtió Imizcoz, "el individuo se subordina a las reglas del grupo y ello no puede ser removido por efecto de la acción vincular, pues se trata de reglas anteriores al sujeto que se imponen de manera imperativa" (1996, pp. 23-24), de modo que no pueden desplazarse las normas étnicas de la relación social. Hay una forma jerárquica de la relación que se aplica no sólo a las relaciones entre los grupos sino también entre los miembros de un mismo grupo o círculo social. Antonia y sus hijos, entonces, no pudieron escamotear las relaciones de subordinación imperantes a nivel de prácticas y de representaciones. Recuérdese que tanto Antonia como su marido "ofrecieron" sus hijos para que actuaran como "criados" del doctor Adrián Cornejo. Así, la diferencia social se concretaba en estrechos vínculos de dependencia personal, deferencia, dominio y subordinación que obligaba al intercambio de servicios, la ayuda y la protección.

Pero no siempre el sujeto que amaba y cuidaba pertenecía a los estratos más relevantes de la sociedad que, mediante esta protección, podía dar lugar al ascenso social de un miembro perteneciente al eslabón extremo. En efecto, miembros de los segmentos medios, en algunas ocasiones, podían ser agentes de este amor y legar algo a alguien que, mediante este vector, mejoraba su posición previa al legado, con la oportunidad de que el legado diera las condiciones objetivas para el cambio de estamento del beneficiado. Los ejemplos de este tipo abundan. Veamos un caso.

Simon Duarte ${ }^{16}$, viudo, portugués, prestamista, poblero y pulpero, integrado a la sociedad cordobesa, al momento de su testamento llevaba, al menos 15 años viviendo en la ciudad. Lo encontramos en numerosos documentos oficiales actuando como testigo en juicios o firmando conciertos de diferente índole. A lo largo de su vida tuvo un crecimiento económico relativo pues su capital económico, seguramente con altas y bajas, varió en estos 15 años de 100 pesos a 450 aproximadamente. Podía alegar vínculos verticales hacia arriba (de naturaleza económica, como prestador de miembros de la élite y poblero ${ }^{17}$ ) y hacia abajo (con una india de la jurisdicción, con la que se casa), así como vínculos horizontales (de naturaleza económica, amical y afectiva, como prestador, pero también simétricos con otros portugueses de la ciudad). Más esquemáticamente, para arriba, vínculos comerciales; para abajo, de amor; horizontalmente, la amistad. Los vínculos horizontales son los más numerosos y relevantes: dejaba a dos comerciantes portugueses,

${ }^{16}$ AHPC. Reg.1, Tomo 36, Años 1620-1621, Testamento de Simón Duarte, 8/IX/1620, Fs. 103 r-104v y Codicilo, 12/X/1620, F. 213r

${ }^{17}$ María, su mujer, recibió del alférez Agustin Ruiz Castelblanco cien ovejas, que Simón Duarte declara repartir entre los indios de la encomienda de Castelblanco y de Blas de Peralta, "para descargo de su conciencia", posiblemente por haberse desempeñado como poblero en estas encomiendas.

Tiene un abanico amplio de deudores: Manuel Rivero, Juan Ruiz Castelblanco, Blas de Peralta; Pedro de Avalos, Juan Franco, Pedro de Chaves, Alonso de Salvatierra, Baltasar Gallegos, Baltasar Ferreira. Se trata de vecinos importantes de la ciudad, feudatarios, cabildantes y de comerciantes de origen portugués. 
González Navarro y Bixio. Dinámicas sociales, vínculos y confianza en el segmento medio de la sociedad cordobesa...

moradores, como albaceas, curadores y tutores de su hijo. Al momento de establecer lazos seguros de confianza se orientó hacia miembros de su misma nacionalidad.

Simón Duarte estuvo casado con una india, María, con quien tuvo un hijo. Como el propio actor declaraba en su testamento, se casó con ella por amor al niño, para legitimarlo. Estas relaciones amorosas, entonces, de amor filial y posiblemente de amor a su pareja, produjeron reposicionamientos sociales para el niño y para la madre, quien, al casarse "no tenia dote mas de unos bestidillos de poca consideración"18. Este casamiento reposicionó socialmente a la india y aseguró un futuro radicalmente diferente para su hijo, a quien declaraba legitimo y universal heredero de sus bienes.

Al momento de testar ya estaba viudo y con consciencia de su vulnerabilidad. Estaba enfermo y contaba con un caudal aproximado de 400 pesos y era consciente de que perdería parte del pequeño capital que había alcanzado a acumular, si su enfermedad se alargaba impidiéndole trabajar. Pedía que "si tubiere bienes quando muera se pagara lo acostumbrado y si no rruego por amor de Dios me entierren de limosna y el dia del entierro si ffuere ora y si no otro siguiente se me diga la missa que tiene obligacion cantada con su vijilia" ${ }^{19}$. Este reconocimiento implicaba que, a pesar de haber estado claramente integrado a la vida de la ciudad, de haber contado con vínculos más o menos estrechos en todas las direcciones, Simón Duarte era una persona completamente vulnerable, cuya trayectoria de vida, más o menos exitosa, no se correspondía con su modo de morir: estaba internado en el hospital de la ciudad, en una cuja propia de poco valor y pedía que se lo enterrara de limosna. Sin duda, estos vínculos no le garantizaron nada, sólo podía confiar en la cofradía de San Francisco, a la que pertenecía, para que atendieran sus necesidades al momento de su muerte.

Este miembro de los segmentos medios de la ciudad, que contaba con importantes y numerosos vínculos, pudo direccionarlos a lo largo de toda su trayectoria vital, integrándose a la ciudad, adquiriendo reconocimiento social y acumulando un cierto capital. Sin embargo, no le garantizaron la protección frente a la adversidad. Tampoco estos vínculos parece que hayan permitido un cambio social radical. Pero lo que es interesante de este caso es la situación conocida pero no generalizada y que era contraria a la mentalidad estamental, del casamiento cristiano con una india de encomienda de la ciudad. Esto es lo que llama la atención, advierte sobre los desplazamientos entre la norma y la práctica, y nos permite visualizar que estos segmentos medios tenían la posibilidad de habilitar el cambio social y cultural de la población indígena ${ }^{20}$. Este sector estaba conformado por sujetos que en tanto pacientes de estas relaciones amorosas, tuvieron la capacidad de ascender a esta franja social (negra Antonia), o pudieron ser agentes de estas transformaciones (Simón Duarte). Es claro, sin embargo, que estos casos atípicos no fueron suficientes para cambiar las representaciones y valores que la sociedad tenía sobre sobre las uniones matrimoniales, las relaciones de pareja y las diferencias étnicas

\footnotetext{
${ }^{18}$ AHPC. Reg. 1, Tomo 36, Años 1620-1621, Testamento de Simón Duarte, 8/IX./1620, Fo. 103v.

${ }^{19}$ AHPC. Reg. 1, Tomo 36, Años 1620-1621, Testamento de Simón Duarte, 8/IX/1620, Fo. 103v.

${ }^{20}$ A.C. 11 de febrero de 1616 y 20 de febrero: Simón Duarte (pulpero) contra el alférez Ruiz de Castelblanco. 25 de agosto.
} 
o de linaje en el orden social. La prueba de ello son las investigaciones sobre familia en Córdoba que demuestran que, desde el siglo XVII y hasta mediados del XIX, la exogamia matrimonial fue excepcional. ${ }^{21}$

Los casos estudiados muestran que en el segmento medio de la sociedad el vínculo amoroso pudo actuar como transformador de una realidad social y posibilitó la movilidad social ascendente de un individuo a la categoría socioétnica superior.

\section{El lazo de amistad}

La amistad fue también un importante determinante que pudo cambiar la situación de no pocos habitantes de la Córdoba colonial. En lo que concierne a las relaciones de amistad horizontales, el vínculo parece haber cumplido más bien una función de protección, como puede observarse en aquellas situaciones iterativas en la documentación en las que un amigo salía como fiador de otro o pagaba una deuda evitando que fuera apresado. Es el caso, por ejemplo, del mercader Gaspar de Alpuen, quien fue denunciado por el mercader Lucas Rodríguez por deudas y que encontró en Francisco Duarte, Juan Madera, Ruy de Sosa y Hernán Suárez Maldonado fiadores del saneamiento de sus bienes. Se trata de relaciones horizontales, de amistad, camaradería y algo de interés por parte de miembros de su misma franja y nacionalidad ${ }^{22}$.

Cuando la amistad afectaba a vínculos verticales, es difícil separar esta noción de amistad del clientelismo, y ésta, a su vez, de las relaciones laborales y comerciales, en especial si pone en relación a sujetos muy separados socialmente. Así por ejemplo, Andrés de Contreras, mayordomo y soldado, recibió indios de servicio de parte de Alonso Martín de Zurita, por razones que se mencionan como de amistad y parentesco, pero que, según consta en el mismo expediente, también se fundan en el hecho de que Contreras había sido soldado de Alonso Martín de Zurita, feudatario, cumplió sus funciones de apoyo a campañas de pacificación junto a él y lo acompañó en corridas a la tierra en la búsqueda de indios.

“...Alonso Martin dio al dicho Andrés de Contreras y a su muger Ysauel Garcia la yndia Catalina como a en la pregunta y se lo oyo a la dicha Ysabel Garçia que se la auia dado el dicho Alonso Martin por amistad y parentesco y por auer sido la dicha Ysabel Garcia madre de Francisco Rodrigues marido de la muger del dicho Alonso Martin y esto rresponde..."23.

En efecto, Zurita y Contreras se encontraban, además, vinculados a través de sus respectivas esposas. Sin duda, los indios que recibiera Contreras de mano de Zurita,

${ }^{21}$ Entre el 1,5 y el 2,5 \% aproximadamente. Incluso, en la primera mitad del siglo XIX estos porcentajes descienden hasta el 1\%. Ferreyra, María del Carmen, 1994, pp. 5-23.

${ }^{22}$ AHPC. Esc. 1, Leg. 9, Exp. 4, Año 1599, Demanda de Lucas Rodríguez contra Gaspar de Alpuen por cobro de dinero, Fs. 303-327.

${ }^{23}$ AHPC. Esc.1, Leg. 12, Exp. 6. F. 221v. El subrayado es nuestro. El caso de Andrés de Contreras está desarrollado en González Navarro, 2013. 
González Navarro y Bixio. Dinámicas sociales, vínculos y confianza en el segmento medio de la sociedad cordobesa...

se relacionaban también con este vínculo familiar lejano que los unía. De modo que la relación clientelar, la amical y la parental se conjugan para que un miembro del segmento intermedio de la sociedad pueda contar con algunos atributos que le confieren valor social. Si el puñado de indios al que accedió Contreras no determinó un cambio en su situación social, sí mejoró mucho su imagen, como sucedió con no pocos soldados del primer período de conquista, cuando aún había una suficiente masa de población indígena por repartir. En estos casos, nuevamente se apeló a la amistad, como un modo de mencionar el clientelismo. Don Alonso de la Cámara, declaraba que "es berdad que muchos soldados tienen seruicio adquerido en la guerra y otros tienen serbizio que les dan por amistad y otros abidos por otras bias" 24 .

Es evidente que las relaciones más o menos estrechas que los miembros de este segmento medio tuvieron con los cabildantes o beneméritos eran de primera importancia para su integración plena a la ciudad, para la acumulación de capitales o para resultar favorecido en un fallo de la justicia. Los ejemplos que podríamos traer a colación abundan en toda la colonia. Recordemos dos o tres casos. Por lo general, son españoles peninsulares y portugueses de este segmento los que mejor pueden relacionarse y los que, por lo tanto, mejor se posicionan socialmente.

Un caso que merece ser considerado, es el de Juan Bizente, pulpero, quien solicitó ser admitido como vecino con todos los privilegios al cabildo de la ciudad y la obtuvo. Es excepcional porque es uno de los dos únicos casos relevados en todo el siglo ${ }^{25}$ y porque incluso, para esa misma época el cabildo proponía a la Audiencia de Charcas una definición de "vecino" que involucraba la posesión de un feudo (Doucet, 1972). En ese momento Córdoba no tenía más de 40 vecinos. Italiano, morador en la ciudad desde hacía 12 años, pedía el 13 de diciembre de 1605 la vecindad y el cabildo se la otorgaba casi inmediatamente, el 25 de febrero de 1606, previa información sobre sus cualidades, específicamente, si era hombre honrado, si había vivido quieta y pacíficamente en la ciudad, si tenía casa y hogar permanente, si nunca se había ido a vivir a otra parte, si había colaborado en todo lo que se le había pedido (soldados, etc.). Fueron testigos miembros de la elite, cabildantes y reconocidos ciudadanos. Los capitulares admitieron a Juan Bizente por vecino y mandaron que goce de los privilegios y exenciones que los vecinos de esta ciudad deben gozar (Santillán Vélez, 1883).

Lo interesante es que este mismo pulpero estuvo, unos años atrás, condenado al pago de multa y prisión en varias oportunidades por venta de vino a indios y negros ${ }^{26}$, por no contar con vara para medir en su pulpería ${ }^{27}$ y por precios

${ }^{24}$ AHPC. Esc.1. Leg. 12. Exp.6. F. 241r. El subrayado es nuestro.

${ }^{25}$ El segundo caso está fechado el 22 de septiembre de 1610 y corresponde a Bartolomé Gómez, quien presenta provisión y recaudo pidiendo ser recibido por vecino de la ciudad. Fue recibido por tal vecino $y$ se le mandaron guardar las honras y preeminencias que se guardan a los demás vecinos.

${ }^{26}$ AHPC, Esc. 1, Leg. 13, Exp. 4, Año 1602, Fs. 82r-88v.

${ }^{27}$ En 1600 el nombre de Jhoan Bizente figura en una petición que hace un conjunto de pulperos al cabildo de la ciudad, seis en total, en la que se apela un auto anterior del cabildo en el que se los condena a 6 y 12 pesos y costas en reales porque no tenían peso y vara y usaban las prestadas, entre otras demandas. El 18/05/1600 se reducen algunas condenaciones y se confirman otras, entre las que está a Juan Bizente, por no tener vara de medir. Santillán Vélez, 1882, T. 3. 
$\operatorname{excesivos}^{28}$. Sin duda, de no haber mediado las relaciones mencionadas con quienes testimoniaron a su favor, ello no hubiera sido posible.

El platero Juan López Reina, vecino, con 16 años de residencia en la gobernación, fue acusado por el encomendero Gerónimo de Bustamante de fundir moneda de plata (tostones de plata de a ocho reales el peso) con el objeto de realizar tazas, jarros, cubiletes y otros objetos ${ }^{29}$. Este mismo encomendero presentó, como testigos, a otros miembros selectos del reducido grupo de vecinos de la ciudad. Lo interesante es que, todos ellos, testificaron en favor del platero y declararon desconocer esta situación. La justicia falló en favor del platero y G. de Bustamante pidió apelación ante la Real Audiencia, que le fue otorgada. Desconocemos qué llevó a G. de Bustamante a hacer esta denuncia y por qué estaba tan ensañado en que la justicia actuara contra el platero, pidiendo incluso, pena de muerte $^{30}$, pero de este juicio nos interesa destacar que, según expresaron todos los testigos, un grupo de al menos seis beneméritos (Bernabé Mexía, Juan de Ludueña, Baltasar Gallegos, Miguel de Moxica), un importante comerciante (Pedro de Soria el joven), un estante, Andrés Mexía, y un mercader de paso por la ciudad, Bartolomé Navarro, en el término de menos de un mes estuvieron todos juntos o de manera individual, en la casa del platero conversando sobre sus productos y su viaje al Perú. Esto es, la casa del platero era algo así como un lugar de reunión del artesano con los cabildantes (dos de ellos eran en ese momento alcaldes) y esta amistad le valió de reaseguro frente a tamaña acusación.

Los casos presentados ponen de manifiesto que los vínculos de amistad que construía el sujeto de los sectores medios con otros de su mismo nivel podían protegerlo, pero no promovían cambios significativos en ninguna de las dos partes. Por el contrario, este ego estaba en condiciones de promover cambios culturales y sociales en miembros del grupo inferior por efecto de la relación de amistad/clientelismo/trabajo como en el caso de relación artesano/aprendiz que a su vez afectaba a su estima social en tanto pasaba a ser patrón de subordinados. Cuando el vínculo se establecía en sentido ascendente, el ego experimentaba una mejora significativa en su valía y estima social (devenir vecino), en sus condiciones de vida (recibe donaciones por ejemplo) y en sus relaciones con las justicias de la ciudad (no recibir testificaciones en contra). En relación a la amistad, el vínculo significa por sobre todas las cosas, el beneficio de la protección.

\section{Vínculos laborales y comerciales}

La confianza fue un valor que también posibilitó el funcionamiento de la economía. En Córdoba colonial, donde la economía monetaria y la economía natural

\footnotetext{
${ }^{28}$ Es más, se infiere que ha tenido algún otro problema con la justicia por precios excesivos en su pulpería pues una hoja suelta encontrada en el Archivo Histórico de Córdoba expresa: "Arançel que se da a Jhoan Visente pulpero de las cosas que a de bender en su pulperia las quales se le manda benda a los precios siguientes", luego de lo cual se acompaña la lista de productos con sus precios. Al final se dan una serie de instrucciones que son indicativas de que tuvo un problema con la ley, tales como que no debe excederse en los precios, la pena que se le pondrá, que no venda vino a indios o negros, etc. Esc.1. Leg. 18. Exp. 1. Fo. 1v Año 1605.

${ }^{29}$ AHPC. Esc. 1, Leg. 1, Exp. 6. Año 1585. López Reyna Juan, Su proceso criminal.

${ }^{30}$ Posiblemente, debido a que el platero se negó a hacerle un cubilete a cambio de lienzo y le pidió plata para ello porque, según declaró, quería irse a Perú y llevar plata y no lienzo.
} 
convivieron a lo largo de todo siglo XVII (Garzón Maceda, 1968; Gelman, 1987), el crédito fue condición necesaria para la circulación de productos. Prestar y pedir prestado fueron acciones necesarias y absolutamente centrales para la vida de una ciudad colonial como Córdoba, que dependía de los circuitos comerciales regionales (Assadourian, 1982), y donde las operaciones pequeñas y grandes pocas veces se realizaban al contado.

Danièle Dehouve (1993) contribuye a iluminar conceptualmente las diferentes formas jurídicas que adoptó el préstamo durante la época colonial. Para comprender esta dinámica económica es necesario saber que la "usura" ${ }^{31}$ era condenada por la Iglesia católica, de manera tal que nadie podía prestar dinero con intereses. No obstante estas prohibiciones, la sociedad implementó tanto en España como en América ciertos mecanismos o formas jurídicas que evadieron de forma sutil pero repetidamente la usura. Así surgieron modalidades legales como las "cartas de obligación", el "censo consignativo", el "depósito irregular", el "fiado", el "avío" y los "censos" (Dehouve, 1993, pp. 20-21). Tanto los censos que brindaban las instituciones eclesiásticas como las cartas de obligación fueron las modalidades jurídicas de crédito más utilizadas en estas latitudes de América, según consta en los libros de protocolo de escribanos. Cabe señalar, sin embargo, que fueron las últimas las más frecuentes entre los sectores medios, a menudo imposibilitados de ofrecer una garantía de hipoteca sobre algún inmueble.

No es fácil caracterizar en unas líneas los vínculos laborales y comerciales que desarrollaron y caracterizaron a los sujetos del entremedio, el alcance de estos vínculos y la fuerza que tuvieron para activar algún tipo de cambio o desplazamiento social. Sabemos que los vínculos sociales se regían por sus propias reglas y prácticas establecidas (Imizcoz, 1996, p. 18). Si nos concentramos en los vínculos laborales y comerciales podemos afirmar que algunos de ellos estaban institucionalizados y otros no; podían basarse en relaciones horizontales o verticales, según el caso (Ponce Leiva, 2007); algunos se desarrollaban al interior de la organización doméstica y otros, entre diferentes organizaciones.

Los sujetos que formaban parte de estas organizaciones domésticas no permanecían aislados sino que establecían vínculos y relaciones en todos los niveles. En efecto, tal como ha señalado José María Imízcoz, es necesario romper con ciertas falacias que identifican la "diferencia social" con la de "distancia social" o "separación", paradigma que se puede aplicar a las sociedades contemporáneas pero no a las del Antiguo Régimen (Imízcoz, 1996, p.14). Los sujetos sociales se relacionaban entre sí a lo largo y ancho de la escala social y los vínculos laborales y comerciales son una prueba cabal de ello: sociedades comerciales, compañías entre artesanos y encomenderos, contratos entre artesanos y aprendices, contratos entre tenderos y comitentes, contratos

\footnotetext{
${ }^{31}$ La usura podía tener lugar cuando se efectuaba el préstamo de ciertos bienes en los que no se podía distinguir la posesión del uso: por ejemplo los cereales, los rebaños y el dinero. Una vez prestados estos bienes seguían produciendo. La usura se producía si el acreedor percibía un interés; entonces, cometía pecado mortal y adquiría la "obligación de restitución" (para ser perdonado por su confesor debía devolver los réditos). Con base en esta prescripción, sólo era lícito el arrendamiento de tierras sin cultivar, pero no huertas, siembras, rebaños ni dinero (Daniele Dehouve, 1993).
} 
entre grandes y pequeños comerciantes, etc. Estas relaciones laborales o comerciales adoptaban la forma de un contrato entre particulares, aunque no en todos los casos estos acuerdos se realizaban formalmente ante un escribano público.

La realidad cordobesa de fines del siglo XVI y primera mitad del XVII muestra que algunos sujetos eran más susceptibles de inspirar la confianza en su entorno, basados en una reputación que habían ido construyendo a lo largo de la vida, cimentada en el cumplimiento de su palabra empeñada y sus contratos pactados y/o firmados en base a sus repetidos actos que pudieran ser observados y corroborados por la comunidad en la cual desplegaba su actividad. Los sectores medios muestran una clara preocupación por resguardar su reputación, cimentada en el recto proceder. En un contexto donde la protección, la seguridad social, la gestión de los recursos y otros servicios, no eran asegurados por el Estado, los vínculos sociales eran particularmente valiosos, en especial si nos referimos a los sectores medios cuya vulnerabilidad era característica.

Algunos contratos, convenios y compañías que involucran a los sujetos de esta franja social intermedia entre fines del siglo XVI y principios del XVII implicaron relaciones horizontales que pusieron en marcha empresas comerciales como la de Francisco Colman y Pedro Maldonado, ambos oficiales carpinteros que trabajaban asociados en una misma compañía $(1594)^{32}$ o la compañía comercial de Hernando Suárez Maldonado vecino morador y Francisco Casado fundada para la venta de mercaderías en Santiago del Estero (1598) ${ }^{33}$. Otras relaciones económicas eran más esporádicas y fluctuantes como la de Juan Bizente pulpero que compraba vino a Francisco de Narbáez mercader y tendero (1614). Estos vínculos horizontales se enlazaban con la confianza y la necesidad de protección o resguardo pues era común el reconocimiento, mediante testamento, de la tenencia o guarda de importantes bienes. Así por ejemplo, Simón Duarte, tendero de origen portugués, morador y enfermo en el hospital, declaraba bajo testamento que el mercader Manuel Rivero le tenía en guarda 350 pesos, una silla brida y una capa $(1620)^{34}$. Pero aunque los vínculos horizontales abundaban, no son los más representados en las fuentes documentales. Ellos tuvieron la capacidad de ampliar el capital económico de las partes implicadas pero no lograron producir cambios significativos en la vida de los sujetos, sino más bien se relacionan con la estabilidad y las formas de subsistencia. Fueron, en todo caso, los vínculos verticales los que resultaron pasibles de producir desplazamientos o cambios más o menos relevantes en los miembros de los segmentos medios.

Las relaciones verticales que conjugan trabajo, amistad y clientelismo se establecen en sentido contrario, esto es, desde los sectores medios a las más bajas escalas del orden social y son las que relacionan, por ejemplo, artesanos y aprendices u oficiales. Las relaciones entre estos dos tipos de agentes no parece que fueran difíciles o tensas y en la mayoría de los casos encontramos que la convivencia en un mismo espacio soldó vínculos más o menos estrechos que llevaron, incluso en algunos casos, al casamiento

\footnotetext{
${ }^{32}$ AHPC. Reg. 1, Tomo 7, F. 200r, 18 de octubre de 1594.

33 AHPC. Reg.1, Tomo 10, F. 125r, 23 de febrero de 1598.

${ }^{34}$ AHPC. Reg. 1, Tomo 36, F. 103r, 8 de septiembre de 1620.
} 
González Navarro y Bixio. Dinámicas sociales, vínculos y confianza en el segmento medio de la sociedad cordobesa...

entre el aprendiz y la hija del maestro artesano. Los aprendices podían ser indios, mestizos, españoles o portugueses pobres que, mediante el aprendizaje de un oficio, pretendían forjarse un futuro más o menos seguro en una ciudad en ciernes, que requería de todos los servicios, incluso los más elementales. En este sentido, interesa destacar el relevante papel que cumplieron estos artesanos en el campo del cambio cultural, enseñando las técnicas de la profesión y acogiendo a estos aprendices en su casa, en contacto permanente: "los maestros artesanos fueron también (...) parte importante del proyecto colonial y del cambio cultural que éste implicó" (González Navarro, 2013).

En este sentido, también los artesanos, en el ejercicio de su función, pueden considerarse, de alguna manera, vectores de desplazamientos sociales en el interior del mundo colonial. En los obrajes, a pesar de las diferencias que pudieran existir, no se producían deslizamientos sociales notables, ya que los nativos, en tanto encomendados, estaban siempre sujetos al amo. En los talleres, por su parte, existía un vínculo más paternalista entre maestro y aprendiz -que no se advierte en los obrajes- donde el segundo no sólo imitaba las habilidades manuales sino también los hábitos, costumbres, y apariencia externa. El subalterno era consciente de que la asunción de ciertos diacríticos (el "hábito de español", el oficio, la religiosidad, maneras de hablar y comportarse) podía contribuir a mimetizarlo con los españoles y con ello a integrarlo socialmente.

Tal como ocurría en el seno de las organizaciones domésticas amplias, en el interior de las más pequeñas, como la de los artesanos, existían una serie de reglas compartidas y jerarquías establecidas. La unidad parental convivía con otros dependientes en el seno de la casa/taller. Los aprendices vivían bajo el mismo techo de un oficial artesano que no sólo les transmitía su saber específico sino que le brindaba comida, vestido, y a menudo, atención médica, obligaciones que quedaban claramente especificadas por contrato. La casa/taller era una esfera que, en una sociedad carente de estructuras estatales de seguridad social, podía garantizar el sustento y amortiguar las calamidades o penurias que pudieran acaecer a sus miembros. Así por ejemplo Juan de Morales, maestro platero, se comprometía en 1620 a enseñar el oficio a Diego de Tapia mancebo residente de la ciudad, por el lapso de 4 años, en el que además se obligaba a dar de vestir, comer y curar en sus enfermedades. A cambio de estos beneficios, Tapia debía servirlo en todo lo que mandara Morales ${ }^{35}$. Casos de este orden encontramos con frecuencia en los libros de protocolos, donde seguramente se encuentran ausentes muchos otros contratos realizados de palabra entre sujetos de similar calidad y condición. Estas relaciones claramente verticales podían, con el correr del tiempo, producir efectos positivos en aquellos sujetos de inferior condición, ya que el aprendizaje de un oficio o saber útil podía contribuir a gestar una reputación y seguidamente despegarse de la dependencia de su amo, tal como se observa con el indio Hernando, oficial zapatero, oriundo de Chile, que en 1642 trabajaba bajo contrato en el taller de Felipe de Torres zapatero ${ }^{36}$, y años después se había marchado a Buenos Aires y andaba en traje de español, según indicaba el propio Torres en su testamento ${ }^{37}$.

${ }_{35}$ AHPC. Reg. 1, Tomo 36, Año 1620-21, Fs. 209-10, 13 de septiembre de 1623.También Reg.1, Tomo 5, Año 1589-90, Fs. 50v-51r, 4 de junio de 1591.

${ }^{36}$ AHPC, Reg. 1, Tomo 53, Año-1641-42, F. 140v.

${ }^{37}$ AHPC, Reg.1, Tomo 111, Año 1657-58, F. 112v-116r. 
Otro tipo de vínculos verticales podían ser más beneficiosos para el artesano, si se establecían hacia arriba en la escala social. Este tipo de relaciones podían quedar instituidas formalmente a través de una "compañía" como la de Juan de Soria vecino y Xayme del Valle, residente (1592); la compañía se formó para la fabricación de vidrio, el primero se comprometió a poner el espacio físico para la ubicación de los hornos, sus carretas y bueyes para cargar piedras, los indios necesarios y la paga de un ayudante para los hornos. Xayme del Valle debía aportar su conocimiento en el oficio para la fabricación de vidrios. La comercialización sería a costa de ambas partes, en especial si las carretas iban más allá de Salta ${ }^{38}$. Aquí se advierte que el contrato era claramente ventajoso para el artesano que poseía los saberes especializados, ya que no arriesgaba casi nada, mientras Juan de Soria ponía todo el capital. No todos los acuerdos para la formación de compañías eran tan desiguales. La mayoría de estas compañías que involucraban a los artesanos, se realizaban con un socio capitalista -generalmente un encomendero- que ponía como puesto principal la infraestructura y los indios de encomienda para realizar la labor acordada (González Navarro, 2014). Pocas veces estas compañías implicaban tareas cuya realización se efectuaba en la traza de la ciudad. La mayoría de las veces la labor se ubicaba en una estancia u obraje a las afueras. En este contexto, el artesano quedaba en cierta medida incorporado a una organización doméstica amplia (donde generalmente el socio capitalista era la cabeza) y debía atenerse a las normas de la casa, como un dependiente jerarquizado. Esto se observa particularmente en aquellos artesanos que cumplían además el rol de pobleros o mayordomos de encomienda, en tanto se encargaban de dirigir el trabajo indígena, enseñar el oficio a los nativos y a menudo también evangelizar y atender a los indios enfermos. Estos mayordomos/artesanos expertos, se convertían con el tiempo en la mano derecha del encomendero, en tanto actuaban en su nombre, merced a los vínculos de confianza y fidelidad que había logrado configurar. En virtud de esta confianza también ejercían el poder, el castigo y el perdón entre los integrantes de la encomienda que regenteaban (Ver. González Navarro y Grana, 2014).

Aunque la mayoría de los artesanos y mayordomos permanecían en el segmento medio a lo largo de toda la vida, algunos de ellos, merced a ciertos vínculos logrados y en especial a través relaciones "clientelares" (Imizcoz Beúnza, 1996) entabladas con poderosos vecinos de la ciudad, podían mejorar su situación de manera considerable. Así se desprende por ejemplo de las trayectorias de vida de Sebastián Casero y de Antonio González. El primero era un mestizo, hijo natural de Pedro Casero español, y se había desempeñado por largos años de trabajo como mayordomo de la encomienda y obraje de Soto perteneciente a Luis de Texeda y Guzmán. Su mestizaje cultural asomaba por los cuatro costados, casado con una india del obraje pero con pretensiones de señor, que se reflejaban en su espada y daga, su tahalí y espuelas de plata, sus sombreros, su crucifijo de madera y los manteles y "servilletas" -objeto poco usual este último- que declaraba en su testamento, entre tantos otros ${ }^{39}$.

\footnotetext{
38 AHPC. Reg.1, Tomo 6, Año 1592, Fs.153r-v, 6 de mayo de 1592.

${ }^{39}$ AHPC, Esc.1, Leg. 80, Exp. 2, F. 48v. Memoria de sus bienes de 1640.
} 
González Navarro y Bixio. Dinámicas sociales, vínculos y confianza en el segmento medio de la sociedad cordobesa...

Por su parte, Antonio González, portugués, también había ocupado un rol similar como administrador de la estancia de Costasacate, perteneciente al ex gobernador Pedro Luis de Cabrera, donde en la primera mitad del siglo XVII había funcionado un obraje indígena, más tarde reemplazado por mano de obra esclava de origen africano. De manera llamativa, en ambos casos, los sujetos habían establecido estrechos vínculos de confianza con sus poderosos amos, a tal punto que al momento de testar ambos afirmaban que sus amos les adeudaban años de salarios por su trabajo. Esto, sin embargo, no parece haber ido en menoscabo de la situación de los mayordomos, por cuanto ninguno manifestaba haber pasado necesidades. Más aún, ambos poseían bienes, y realizaban negocios lucrativos con otros vecinos o residentes de la ciudad en el marco de la estancia/obraje donde tenían asiento sus actividades. Así por ejemplo Sebastián Casero expresaba por testamento varias acreencias que le adeudaban vecinos reputados de la ciudad con los que había entablado negocios, como el cap. Don Alonso de Vera y Zárate y el cap. Ángelo de Castro.

Se advierte particularmente en el caso de Antonio González que sus vínculos de lealtad y fidelidad para con su amo le fueron beneficiosos, en la medida en que a lo largo de la vida pudo comprar 2 esclavos, recibió además como parte de pago por sus servicios 8 esclavos y como donación voluntaria de su amo, una estancia de media legua de largo, en las cercanías del Río segundo. En la carta de donación que había efectuado Cabrera en 1649 expresaba las razones de la donación: "por quanto tengo amor y voluntad a Antonio Gonsalez por lo mucho que me a sserbido y buenas obras que de el e rrezibido y obligación en que me hallo"40.

En este caso, los vínculos de González con la familia Cabrera -descendiente del fundador de la ciudad de Córdoba- había incidido positivamente en el buen pasar de este mayordomo, de origen portugués bastante modesto. A lo largo de su vida no sólo había logrado acumular un capital semoviente e inmueble, de relevancia, sino que además había logrado dotar a su hija natural Juana González con 3050 pesos corrientes, en géneros diversos, suma por cierto muy considerable, si tenemos en cuenta los capitales de la mayoría de los sectores medios. Su hija, ya casada con Pedro de Acuña se había instalado en la estancia que su padre le heredara y allí habría transcurrido su vida familiar, llegando a tener 9 hijos. Este es un ejemplo de la forma en que apenas en el transcurso dos generaciones de la familia González (Antonio González padre y Juana González su hija) se produjo un desplazamiento social, merced a un contexto que favoreció las relaciones (verticales) clientelares donde la confianza y la lealtad eran la base fundante.

Aquí el vínculo cambia realmente las relaciones de poder y permite su ejercicio y poder de castigo inusitado, mucho más que los encomenderos. Pero las relaciones y vínculos verticales no sólo eran entablados por los artesanos o mayordomos, sino también por otros sujetos que se ubicaban en el entremedio de la escala social. Quienes ejercían el arte de curar (médicos, barberos, cirujanos) tenían la habilidad para tejer relaciones favorables. Así lo ha demostrado Tapia en su estudio sobre la trayectoria de vida de algunos de estos sujetos como Martin de Fonseca, barbero y espadero quien, merced a sus

${ }^{40}$ AHPC, Esc.1, Leg. 121, Exp. 6, F. 195r. 
relaciones y reputación ganada entre la elite logró en 1607 que el cabildo lo autorizara a ejercer la medicina en la ciudad, e incluso el cabildo lo contrató para curar a los enfermos del hospital, a pesar de carecer de títulos que acreditaran su idoneidad (Tapia, 2016).

También los comerciantes tenían una particular habilidad para desarrollar lazos tanto hacia arriba como hacia abajo en la escala social. Es el caso de Francisco de Narbáez, tendero, que a su muerte, en 1614, mantenía estrechos vínculos comerciales tanto con sujetos de reconocido linaje y tradición en la ciudad-como por ejemplo Alonso de la Cámara, Tristán de Tejeda, Juan Céliz de Quiroga y Juan de Ávila y Záratecomo con artesanos acomodados como Francisco Méndez sombrerero que poseía un taller con varios esclavos propios; y otros sujetos más modestos y menos reputados como el pulpero Juan Bizente y el indio Juan Amaro, entre otros. Claramente algunos comerciantes de mediano nivel como Narbáez se relacionaban con todos los habitantes de la ciudad, independientemente de su condición social y podían llegar a constituirse en verdaderos "brokers" en tanto generalmente no poseían recursos de primer orden (inmuebles, esclavos, dinero en cantidad, títulos) pero tenían estrechas relaciones con sujetos que sí los poseían y de esta manera tenían el poder para circular información, obtener mercaderías en consignación, movilizar los recursos de terceros y ejercer influencias a través de su acción de mediación (Boissevain, 1974, p. 147). Su rol de intermediarios podía generar no sólo la confianza y credibilidad por parte de los sujetos que se relacionaban con ellos sino generar un crédito a su favor.

En este sentido, cuando pretendemos dar cuenta de las particularidades que presenta la configuración de la sociedad colonial, es posible advertir nuevos contrastes y diferencias reconocibles a partir del tipo de crédito al que accedían los diferentes segmentos ${ }^{41}$. En el caso de Córdoba, observamos que los tipos de crédito no sólo permiten delinear los límites entre diferentes sectores sociales (en función de su capacidad para asegurar la devolución y pago de la suma prestada o producto entregado en adelanto) sino que además el crédito permite dar cuenta de los vínculos de confianza que eran capaces de tejer los sujetos en torno a sí y configurar una red los suficientemente densa que les permitiera amortiguar los posibles vaivenes de la economía y los riesgos.

El comerciante portugués Francisco de Narbáez es un claro ejemplo de ello. Narbáez, había ingresado por el puerto de Buenos Aires sin licencia, aproximadamente en 1595 y empadronado en 1607 (Binayan Carmona, 1973, p. 229), declaraba tener por entonces un caudal de tres o quatro mil pesos. A su muerte (1614) su tienda estaba nutrida de los más variados objetos muchos de los cuales provenían de otras regiones e incluían desde alimentos (botijas de vino, barriles de confitura, diacitrón y conservas, cajetas de carne de membrillo, pimienta, arroz de Brasil, botijas de aceite y aceitunas, etc.), ropa de la tierra para los indios (sombreros, camisetas, etc.) cordobanes y telas de diversa calidad y origen geográfico (cordellate, paño, ruan, telilla, cambray, tafetán de la China, caniquí de la India, etc.), herramientas (tijeras de sastre, alfileres, etc.), hasta bienes de uso cotidiano

\footnotetext{
${ }^{41}$ Para el caso europeo Jean Philippe Priotti destaca en el mismo sentido, que los sistemas de crédito a largo plazo fueron un rasgo posible de diferenciación entre los grupos mercantiles del siglo XVI (Priotti, 2002, p. 47).
} 
González Navarro y Bixio. Dinámicas sociales, vínculos y confianza en el segmento medio de la sociedad cordobesa...

como cera del Paraguay, candelas de cera del Brasil y jabón ${ }^{42}$. Si bien no se realizó la tasación de sus bienes, los contadores nombrados realizaron un inventario pormenorizado y venta en almoneda para saldar las deudas contraídas y cobrar las cuentas pendientes del difunto. El resultado de este largo proceso muestra que Narbáez, a su muerte, tenía 1764 pesos en bienes, ninguno de los cuales estaba constituido por algún inmueble. No obstante, luego de los alcances y descargos, pago de costas y demás asuntos sólo quedó para repartir a sus herederos la suma de 239 pesos y 1 real.

A pesar de lo magro de sus capitales luego de liquidados, observamos que este tratante había logrado acceder a las más variadas mercancías que comercializaba en sus dos tiendas, merced a los vínculos verticales y horizontales que había desarrollado. En efecto, la mayoría de las mercancías declaradas en su testamento estaban registradas como productos entregados en consignación por diferentes comitentes. Algunas de las mercaderías habían sido registradas a través de cartas de obligación como ocurrió con Sebastián de Acosta, mientras que otras apenas estaban asentadas en cédulas manuscritas de puño y letra del comitente, sin que hubieran sido labradas ante escribano público. Este pequeño resguardo dejaba un registro de lo entregado en consignación en los libros de Francisco Narbáez que eran llevados cuidadosamente. Teodocio Correa, persona de confianza del difunto, tenía en su poder los papeles de Narbáez y a su muerte fue quien como su albacea pudo dar cuenta ante la justicia de todos los deudores y acreedores. De hecho fue el encargado de redactar por poder su testamento ante la imposibilidad de hacerlo Narváez personalmente. Aquí se observan los vínculos de confianza enlazando las relaciones comerciales a través de la consignación y el albaceazgo.

Bienes entregados en consignación a la tienda de Francisco de $\operatorname{Narvaez}^{43}$

\begin{tabular}{|c|c|c|}
\hline Producto & $\begin{array}{c}\text { Origen } \\
\text { geográfico }\end{array}$ & Comitente \\
\hline Telas de seda & Oriente & Domingo Lorezo \\
\hline Cordellates de colores & & Baltasar de Quiroga \\
\hline $\begin{array}{l}\text { Zarzaparrilla, cordellate, } \\
\text { cordobanes, paño blanco. }\end{array}$ & & Tristán de Tejeda \\
\hline Seda torcida floja & China & Alonso de la Cámara \\
\hline Sayal y lienzo & & Teodocio Correa \\
\hline Cajetas de carne de membrillo & & Juan Céliz de Quiroga \\
\hline Quesos & & Antonio del Rosillo (vicario) \\
\hline Paño & & Juan Rodríguez Navarro \\
\hline Hilo de alambre & & Juan Amaro \\
\hline Espuelas de plata & & José Perez Quevedo \\
\hline Botijas de vino & & Baltasar de Quiroga \\
\hline Botijas de vino & Mendoza & Francisco Sudina \\
\hline Azúcar & & Herederos de Pantaleón Marquez Correa \\
\hline Sombreros & & Francisco Méndez (sombrerero con taller de esclavos) \\
\hline Botijas de vino & Mendoza & Manuel Barros de Acosta \\
\hline
\end{tabular}

${ }^{42}$ Inventario y almoneda de los bienes fincados por muerte de Francisco Narbáez. AHPC, Año 1615, Esc.1, Leg. 35, Exp. 2.

${ }^{43}$ AHPC. Esc. 1, Leg. 35. Exp. 2. Según su testamento de 1614 en f. 29r y ss. 
El cuadro que antecede muestra algunos de los productos que comercializaba Narbáez en su tienda y su origen geográfico, así como también revela que la mayor parte de ellos no habían sido adquiridos por compra directa sino que habían sido entregados por numerosos comitentes en consignación. Esta era, sin duda, una práctica habitual en la época colonial que requería de una apuesta de confianza con un cierto margen de riesgo para el comitente, pero que podía ser relativamente controlado cuando la comercialización de la mercancía se realizaba en el espacio de la ciudad. Los numerosos vínculos comerciales que fue capaz de desarrollar Francisco de Narbáez le dieron la oportunidad de llevar adelante con éxito su tienda, siendo capaz de mantener un movimiento constante de mercaderías de muy variado tipo y origen, con escaso riesgo.

Mayores riesgos involucraban al comercio a larga distancia, puesto que el comitente debía a menudo entregar dinero a cuenta de una mercadería a recibir, o en su defecto remitía ciertos productos que debía cobrar más tarde de manos de un intermediario. El riesgo existía a pesar de las numerosas cartas de obligación que se firmaban para asegurar el cobro de lo invertido. Los vínculos de confianza/lealtad comercial eran un resguardo extra que teñía este tipo de transacciones. Si bien la rentabilidad no parece haber sido elevada dentro de este segmento, el crédito fue un mecanismo que posibilitó a sus miembros una forma de subsistencia. Aquéllos que carecieron o contaron con escaso crédito de confianza, cayeron en el aislamiento social, la pobreza o debieron continuar moviéndose de una ciudad a otra, como nómades, hasta poder lograr construir un entramado de relaciones que les permitiera radicarse definitivamente en un lugar.

\section{Consideraciones finales}

Tal como desarrollamos a lo largo del artículo, los vínculos sociales se presentan como un ámbito especialmente fructífero para dar cuenta de las condiciones de posibilidad con la que contaron los miembros de la franja intermedia de la sociedad colonial para mejorar sus condiciones de vida o producir desplazamientos sociales. En general, no hemos aún relevado en nuestro corpus de análisis grandes novedades en relación a los comportamientos sociales canónicos, esperables, que se configuran según la doxa. Sin embargo, las desviaciones a la norma en las que hemos centrado algunas trayectorias, permiten reconocer algunas biografías atípicas que ponen en escena estrategias de los agentes sea para promover a un tercero, sea para garantizar un mejor posicionamiento en el mismo segmento social intermedio.

Como hemos advertido, la confianza fue un motor vincular que posibilitó (como lo hace actualmente) la constitución de lo social. Estas relaciones de confianza pueden entenderse también, en muchos casos, aunque no en todos, como expresiones de solidaridad que exceden con mucho el ámbito del grupo parental más directo. Y es eso lo que queremos destacar en este artículo: la confianza en la que se basó la amistad, el cariño, el trabajo y el comercio fue una vía no estatuida legalmente y menos aún institucionalizada, pero presente en el orden social que se configura en Hispanoamérica y que habilita cambios sociales y culturales no previstos, tal como lo advirtió Ponce Leiva (2007). Los segmentos medios que estudiamos trabajaron, como los miembros 
González Navarro y Bixio. Dinámicas sociales, vínculos y confianza en el segmento medio de la sociedad cordobesa...

de la élite, a fin de establecer alianzas, relaciones, influencias políticas y económicas que les aseguraran un posicionamiento relevante en el entramado social, estima social y seguridad en todos los terrenos. Pero este trabajo fue diferente y no involucró las mismas estrategias que el que llevaron a cabo los miembros de la elite.

Por una parte, los vínculos en los que hemos visto involucrados a miembros de los segmentos medios no configuraron redes propiamente dichas pues, hasta donde hemos podido observar, comportan pocos actores y estas relaciones son primarias, inmediatas, directas, no densas, a diferencia de las redes que son capaces de construir los poderosos. Por otra, también a diferencia de aquéllos, estos vínculos no se heredan sino que los construyen los individuos en terreno, posiblemente debido a que la población que estudiamos no es originaria de la región sino que corresponde a un paulatino poblamiento de la ciudad. Por lo general el paisanaje parece que cumplió una función central, y esto se advierte particularmente en el caso de la población portuguesa que con frecuencia desarrolló estrechos lazos, aspecto que deberá ser desarrollado en otro momento.

Aunque no hayamos podido visualizar verdaderas redes relacionales, es evidente que estos vínculos ampliaron con mucho la capacidad de acción de los sujetos y que les trajeron a los miembros de este segmento amplios beneficios que van desde mejoras en las posibilidades de trabajo y de vida hasta el cambio rotundo en las condiciones de subsistencia material, especialmente, cuando la confianza involucra también el vínculo amoroso.

En cuanto a la relación entre cambio social y vínculos, la primera observación es que la relación horizontal tiene una importante función de protección y contención social, aunque no incide mayormente en cambios económicos, sociales o culturales de los sujetos. $\mathrm{Al}$ menos, el corpus no habilita este reconocimiento. Más interesantes y fructíferos para la evaluación de estos cambios parece ser los vínculos verticales, pues aunque benefician a ambos, producen cambios relevantes siempre al que se encuentra en el extremo inferior de la relación asimétrica. Es interesante observar hasta qué punto los miembros de este segmento medio tuvieron la capacidad y la posibilidad, efectivamente ejercida, de actuar sobre los grupos más subordinados (indios de encomienda o forasteros, esclavos de origen africano, mestizos huérfanos, etc.) y producir cambios en ellos. Interesa destacar, aunque no ha sido desarrollado extensamente en este trabajo, que al menos para la jurisdicción de la ciudad de Córdoba del Tucumán, fueron estos sujetos quienes más frecuentemente promovieron estos cambios, mucho más que los de los segmentos más altos. El caso de la negra Antonia es, por ello, excepcional. Es más, la elite pocas veces promueve el cambio sino que, incluso pocas veces interactúa directamente con estos sectores más bajos sino que lo hace a través de intermediarios ubicados justamente en la franja media de la población (pobleros, administradores, maestros artesanos, misioneros, pulperos, etc.). Son estos, los encargados, entonces, de promover cambios en las creencias y en las prácticas, aunque es más clara la internalización de una creencia occidental que la práctica según las regulaciones de la elite.

La sociedad colonial temprana fue dinámica-mucho más de lo que lo será en el siglo XVIII-; las relaciones entre sus elementos sufrió variaciones de todo tipo y el ordenamiento adoptó formas inesperadas en más de una oportunidad, lo que neutralizó distinciones 
aparentemente irreconciliables, situaciones que deben haber afectado las sensibilidades y las identidades de las personas involucradas. Si no fueron considerados disidentes fue debido a los procesos de mimetización de que fueron agentes estos "disidentes".

En este segmento social intermedio las relaciones sociales, según hemos podido apenas atisbar, no fueron tanto un capital promotor de poder sino, fundamentalmente, de capital social direccionado hacia la propia imagen como sujeto digno, habilitador de la integración social, con las consecuencias que este reconocimiento traía a nivel de opciones de trabajo y de acumulación de otros capitales. Este era el beneficio de la relación con los grupos altos, aparte de la protección. Redimensionó estructuraciones sociales sólidas, como la de la vecindad.

Nos preguntamos en qué medida estas nuevas posiciones de sujeto afectaron a lo colectivo. Sin duda, muchas de las situaciones tratadas fueron excepcionales e individuales pero de alguna manera generaron dinámicas que los excedieron y que repercutieron sobre el cuerpo social mostrando una sociedad diferente, en la que una esclava, vestida de señora, que dormía en cama con pabellón, podía ser propietaria de una tienda frente a la plaza y alternar con lo más elevado de la sociedad de la época o un pulpero, que habiendo actuado en contra de la ley en reiteradas ocasiones, podía ser admitido como vecino.

Los casos estudiados muestran que en el segmento medio de la sociedad el vínculo amoroso pudo actuar como transformador de una realidad social y posibilitó la movilidad ascendente de un individuo a la categoría socioétnica superior. La amistad fue también un importante determinante que pudo cambiar la situación de no pocos habitantes de la Córdoba colonial, aunque para que ello fuera posible se requirió que el vínculo fuera vertical. En lo que concierne a las relaciones de amistad horizontales, el vínculo pareció cumplir más bien una función de protección. Estas relaciones de amistad/clientelismo/parentesco habilitaron un juego de poderes complejo que condujo al exceso y al horror, especialmente en el caso de los pobleros, tal como ha quedado registrada en numerosos documentos.

Queda aún considerar los casos contrarios, esto es, enemistad, odio, repulsión, prejuicio (étnico, racial, social), esto es, vínculos de valencia negativa, como agentes de inmovilismo o de cambio.

\section{Referencias bibliográficas}

Araya Espinoza, A. (2006). "El castigo físico: el cuerpo como representación de la persona, un capítulo en la historia dela occidentalización de américa, Siglos XVIXVIII". Historia, No 39, Vol. 2, 349-367.

Assadourian, C. S. (1973).’’Potosí y el crecimiento económico de Córdoba en los siglos XVI y XVII". En: Volumen Homenaje al Doctor C. Garzón Maceda. U.N.C. Dirección General de Publicaciones. Córdoba. IEA. 
González Navarro y Bixio. Dinámicas sociales, vínculos y confianza en el segmento medio de la sociedad cordobesa...

Bridikhina, E. (2007). Teatrum Mundi. Entramados de poder en Charcas Colonial. Plural-IFEA. Perú.

Binayan Carmona, N. (1973). "El padrón de extranjeros del Tucumán de 1607”. Investigaciones y Ensayos, $\mathrm{n}^{\circ} 15,207-239$.

Bixio, B. y González Navarro, C. (dir.). (2013). Mestizaje y configuración social en Córdoba (siglos XVI y XVII). Córdoba, Argentina: Editorial Brujas.

Bixio, B. y González Navarro, C. (2019). "Reflexiones acerca de los segmentos medios en la sociedad colonial temprana de Córdoba del Tucumán, 1573-1620”. Revista Complutense de Historia de América. (En prensa).

Boissevain, J. (1974) Friends of friends: networks, manipulators and coalitions. Oxford. Basil Blackwell eds.

Bretón, V. y García, F. (eds) (2003). Estado, etnicidad y movimientos sociales en América Latina. Ecuador en crisis. Barcelona: Icaria.

Dehouve, D. (1993) "Introducción a la parte histórica”. En: Noëlle Chamoux, Danièle Dehouve, Cécile Gouy-Gilbert, Marielle Pepin Lehalleur (Coords.) Prestar y pedir prestado. Relaciones sociales y crédito en México del siglo XVI al XX. Centro de Investigaciones y Estudios Superiores en Antropología Social. México: Ediciones de la Casa Chata, 19-24.

Doucet, G. (1972). "Feudatarios y soldados en el cabildo de Córdoba". Revista de Historia del Derecho, $\mathrm{n}^{\circ} 2$.

Elias, N. (1989). El proceso de la civilización. Investigaciones sociogenéticas y psicogenéticas. México D. F.: Fondo de Cultura Económica

Elias, N. (1996). La sociedad cortesana. México D. F.: Fondo de Cultura Económica.

Elias, N. (1998). La civilización de los padres y otros ensayos. México D. F.: Norma.

Elias, N. (1999). Sociología fundamental. Barcelona: Gedisa.

Elias, N. (2000). La sociedad de los individuos. Barcelona: Península

Ferreyra, M. C. (1994) "El matrimonio en Córdoba durante el siglo XVII, algunas referencias demográficas". Cuadernos de Historia. № 1, 5-21.

Garzón Maceda, C. (1968) Economía del Tucumán. Economía natural y economía monetaria. (Siglos XVI, XVII y XVIII). Dirección General de Publicaciones. UNC. IEA. Córdoba.

Gelman, J. (1987). "Economía natural-economía monetaria. Los grupos dirigentes de Buenos Aires a principios del siglo XVII". Anuario de Estudios Americanos, Sevilla, XLIV.

Gómez Carrasco, C. J. (2009). Herencia y transmisión del patrimonio a finales del Antiguo Régimen. Diferentes estrategias en la comunidad mercantil y en la élite local (Albacete, 1750-1830). Investigaciones Históricas. № 29, 97-128.

Gonzalbo Aizpuru, P. (coord.) (2013). Amor e historia, la expresión de los afectos en el mundo de ayer. México. El Colegio de México.

González Navarro, C. y Grana, R. (2014). "Mayordomos y regulación de las prácticas sociales indígenas en el interior de las estancias coloniales. La visita de Luxan de Vargas. Córdoba. 1692-1693”. Revista Historia y Justicia, No 3, 166-194. 
González Navarro, C. (2005). Construcción social del espacio en las sierras y planicies cordobesas. 1573-1673. Córdoba, Argentina: Tesis doctoral. Universidad Nacional de Córdoba.

González Navarro, C. (2013). Andrés de Contreras, soldado, mayordomo y sastre. Una aproximación al entre-medio de la naciente sociedad colonial. Córdoba. (siglos XVI-XVII). En B. Bixio y C. González Navarro (dirs.) Mestizaje y configuración social en Córdoba (siglos XVI y XVII). Córdoba, Argentina: Editorial Brujas.

Gould, E. (2008). "Un estudio desde la diversidad: dos familias y sus derivaciones en la Córdoba de mediados del siglo XVII". En: N. Siegrist y M. Ghirardi (Coord.) Mestizaje, sangre y matrimonio en territorios de la actual Argentina y Uruguay. Córdoba. Univ. Nac. de Córdoba.

Imízcoz Beúnza, J. M. (1996). Elites, poder y red social. Las élites del País Vasco y Navarra en la Edad Moderna (Estado de la cuestión y perspectivas). Universidad del País Vasco. Bilbao.

Luque Colombres, C. (ed.) (1952). Actas capitulares de la municipalidad. Archivo Municipal de Córdoba. Tomo 9. Córdoba.

Luque Colombres, C. (ed.) (1974). Actas capitulares de la municipalidad. Archivo Municipal de Córdoba. Tomo 1. Córdoba.

Mantecón Movellán, T. A. (2010). Formas de disciplinamiento social, perspectivas históricas. Revista de Historia Social y de las Mentalidades, Vol. 14, № 2, 263-295.

Martínez Millán, J. (2006). La Corte de la monarquía hispánica. Universidad Autónoma de Madrid. Studa Historica, Historia Moderna. Universidad de Salamanca. 28, pp. 17-61.

Paugam, S. (2012), "Protección y reconocimiento. Por una sociología de los vínculos sociales", Papeles del CEIC, Vol. 2, No 82.

Ponce Leiva, P. (2007) "Versatilidad social y poderes múltiples en la América colonial", Nuevo Mundo Mundos Nuevos [En ligne], Colloques, mis en ligne le 05 janvier 2007, consulté le 27 avril 2018. URL : http://journals.openedition.org/ nuevomundo/3231; DOI : 10.4000/nuevomundo.3231

Ponce Leiva, P. (1998). Certezas ante la incertidumbre. Élite y cabildo de Quito en el siglo XVII. Quito: Abya-Yala.

Presta, A. M. (2000). "La sociedad colonial: raza, clase, etnicidad y género, siglos XVI y XVII”. En: Nueva Historia Argentina. Vol. II. La sociedad colonial. Buenos Aires. Sudamericana. pp. 55-85.

Priotti, J. P. (2002). "Uso material e inmaterial del dinero. Un análisis social para el estudio de los patrimonios mercantiles, siglos XVI-XVII". En: Casado Alonso, H. y Robledo Hernández, (Eds.) Fortuna y negocios. Formación y gestión de los grandes patrimonios (siglos XVI-XX), pp. 45-72.

Rubiolo Galíndez, M. (2013): "De todo un poco. La relativa prosperidad de una familia de carpinteros en Córdoba del Tucumán (ca.1600-1641)”, en B. Bixio (dir.), Mestizaje y configuración social en Córdoba (siglos XVI y XVII), Brujas-UNCSecyt, Córdoba. 
Santillán Vélez, J. (1882). Archivo Municipal de Córdoba. Libro III. Imprenta del Eco de Córdoba. Córdoba.

Santillán Vélez, J. (1883). Archivo Municipal de Córdoba. Libro IV. Imprenta del Eco de Córdoba. Córdoba.

Tapia, J. (2016). “Cirujanos y barberos en la ciudad de Córdoba (1573-1640). Procesos de integración social y representaciones". Ponencia presentada al XXXVI ${ }^{\circ}$ Encuentro de Geohistoria Regional. Resistencia. Chaco.

Undurraga Schüler, V. (2010). “Valentones', alcaldes de barrio y paradigmas de civilidad. Conflictos y acomodaciones en Santiago de Chile, siglo XVIII". Revista de Historia Social y de las Mentalidades. Volumen 14, No 2: 35-71.

\section{Apéndice de fuentes consultadas}

Archivo Histórico de la Provincia de Córdoba (AHPC).

Registro 1: Tomos 1 al 35.

\section{Escribania 1:}

Leg. 1, Exp. 13; Año 1574-76.

Leg. 3, Exp. 7; Año 1590-91.

Leg. 5, Exp. 6; Año 1595-97.

Leg. 6, Exp. 3; Año 1598.

Leg. 7, Exp.1; Año 1598.

Leg. 10, Exp. 1; Año 1600.

Leg. 11, Exp. 2; Año 1601.

Leg. 14, Exp. 6; Año 1604.

Leg. 15, Exp. 1; Año 1604.

Leg. 16, Exp. 8; Año 1605.

Leg. 17, Exp. 12; Año 1605.

Leg. 29, Exp.2; Año 1613.

Leg. 32, Exp. 6; Año 1614.

Leg. 35, Exp. 2, Año, 1615.

Leg. 37, Exp. 1; Año 1616.

Leg. 41, Exp. 2. Año 1618. 